\title{
The potential for estrogen disrupting chemicals to contribute to migration, invasion and metastasis of human breast cancer cells
}

\author{
Philippa D. Darbre \\ School of Biological Sciences, University of Reading, Reading RG6 6UB, UK.
}

Correspondence to: Prof. Philippa D. Darbre, School of Biological Sciences, Hopkins Building, University of Reading, Whiteknights, Reading RG6 6UB, UK. E-mail: p.d.darbre@reading.ac.uk

\begin{abstract}
How to cite this article: Darbre PD. The potential for estrogen disrupting chemicals to contribute to migration, invasion and metastasis of human breast cancer cells. J Cancer Metastasis Treat2019;5:58. http://dx.doi.org/10.20517/2394-4722.2019.22
\end{abstract}

Received: 9 Mar 2019 First Decision: 8 Apr 2019 Revised: 9 May 2019 Accepted: 12 Jun 2019 Published: 20 Jul 2019

Science Editor: William Schiemann Copy Editor: Jia-Jia Meng Production Editor: Jing Yu

\begin{abstract}
Estrogen disrupting chemicals are environmental compounds which mimic, antagonize or interfere in the action of physiological estrogens. They occur naturally (plant phytoestrogens) but the majority are man-made compounds, which, through their use in agricultural, industrial and consumer products, have become widely present in human tissues including breast tissue. Since exposure to estrogen is a risk factor for breast cancer, estrogen disrupting chemicals may also contribute to breast cancer development. This review discusses evidence implicating estrogen disrupting chemicals in increasing migratory and invasive activity of breast epithelial cells, in epithelial-tomesenchymal transition, and in growth of breast tumours at metastatic sites as well as the primary site. Mechanisms may be through the ability of such chemicals to bind to estrogen receptors, but unlike for proliferation, effects on cell migration and invasion are not limited to estrogen receptor-mediated mechanisms. Furthermore, whilst effects on proliferation can be measured within hours/days of adding an estrogen disrupting chemical to estrogen-responsive breast cancer cells, effects on cell migration occur after longer times (weeks). Most studies have focused on individual chemicals, but there is now a need to consider the environmentally relevant effects of long-term, lowdose exposure to complex mixtures of estrogen disrupting chemicals on mechanisms of metastasis.
\end{abstract}

Keywords: Aluminium, breast cancer, estrogen disrupting chemicals, invasion, metastasis, migration, paraben, personal care products, UV filter. 


\section{INTRODUCTION}

Estrogen disrupting chemicals are exogenous environmental compounds that can interfere in the action of endogenous estrogens. Through their ability to bind to estrogen receptors, they may be able to mimic or antagonize the cellular actions of physiological estrogen $s^{[1]}$. They may also influence synthesis, transport, metabolism and clearance of physiological estrogens ${ }^{[1]}$. Some are found naturally in plants (phytoestrogens) or fungi (mycoestrogens), but the majority are man-made compounds to which the human population is widely exposed through their use in agricultural, industrial and consumer products ${ }^{[1]}$. Such compounds are used as components of pesticides and herbicides in agricultural, urban and domestic environments. They are widely used in industrial applications and occur as byproducts of combustion from vehicles, aircraft and ships. These compounds are found as components in plastics, with applications from building materials to food/water containers, in detergents used for cleaning in industrial and domestic settings, and as flame retardants in soft furnishings. A range of components added to personal care products are also now known to possess estrogen disrupting activity ${ }^{[1]}$. Some more specific examples are shown in Table 1. Intake to the human body may be by the oral route (food/water) or inhalation (air pollution) or dermal absorption (products applied to skin or present in the air). So ubiquitous are the many estrogen disrupting chemicals in modern life that exposure is almost never from a single source but rather from multiple sources reflecting not only occupational exposures but also personal lifestyle choices.

Since exposure to estrogens is an established risk factor for breast cancer ${ }^{[2]}$, it is thought that estrogen disrupting chemicals may also contribute to breast cancer development if they are present in human breast tissue at sufficient concentrations ${ }^{[1]}$. Development of cancer is a lengthy and complex process, that originates from a loss of growth control, and culminates in metastatic tumour spread. Both genetic and environmental influences interact to enable the associated hallmarks of cancer to develop ${ }^{[3]}$. The hallmark of sustained cell proliferation in breast cancer is well established as involving estrogens ${ }^{[4]}$ and probably also estrogen disrupting chemicals ${ }^{[5]}$. Since metabolism of some endogenous estrogens gives rise to genotoxic compounds $^{[6]}$ and since some estrogen disrupting chemicals are also genotoxic ${ }^{[1]}$, a role has been recognized in generating genomic instability which is an underlying enabling characteristic of cancer ${ }^{[3]}$. However, the role of endogenous and exogenous estrogens in contributing to the processes of metastatic tumour spread are less well established. This is especially important in the context of breast cancer where the main cause of mortality arises from growth of metastatic tumours ${ }^{[2,7]}$. This review will discuss current evidence suggesting that endogenous and exogenous estrogens can contribute to increasing migratory and invasive activity of breast epithelial cells which are hallmarks of cancer required for the metastatic process ${ }^{[3]}$.

\section{ENDOGENOUS ESTROGENS AND METASTASIS}

Cellular actions of estrogens are mediated through binding to specific receptor proteins ${ }^{[8]}$. There are two types of nuclear estrogen receptors, estrogen receptor $\alpha(E R \alpha)$ and estrogen receptor $\beta$ (ER $\beta)$ which exist as multiple isoforms and which function as ligand-activated transcription factors to influence patterns of gene $\operatorname{expression}^{[8]}$. Final outcomes are dependent on the affinity of ligand binding to receptor, the concentrations of receptors in the target cells and the presence of co-acting factors/transcription factors ${ }^{[8]}$. In addition, estrogenic ligands can also act through binding to membrane-associated molecules such as the G-proteincoupled estrogen receptors ${ }^{[8,9]}$.

Metastasis involves a complex series of events whereby the malignant cells break away from the primary tumour, invade through local tissue, infiltrate circulatory vessels (blood and/or lymph) and at distant sites exit the vessels to from new foci of cancer cell growths (colonization) ${ }^{[7]}$. Endogenous estrogens can influence all these processes including immune evasion and the angiogenesis needed for effective metastatic colonization ${ }^{[10]}$. In their capacity to regulate growth of estrogen-responsive human breast cancer cells $^{[2,4]}$, estrogens can influence metastatic tumour growth at both the primary and secondary sites ${ }^{[2]}$. 
Table 1. Estrogen disrupting chemicals: example compounds, uses in the environment, and sources of human exposure

\begin{tabular}{lll}
\hline Use in the environment & \multicolumn{1}{c}{ Example compounds } & \multicolumn{1}{c}{ Source of human exposure } \\
\hline Plant phytoestrogens & Genistein, daidzein & Edible plant material (diet, dietary supplements) \\
Pharmaceuticals & Ethinylestradiol & Contraceptive pill, hormone replacement therapy, cosmetics \\
Pesticides & DDT, lindane, pyrethroids & Pesticide products, animal fat (diet) \\
Herbicides & Glyphosate & Garden weedkillers \\
Industrial & Polychlorinated biphenyls & Animal fat (diet) \\
By-product of incineration & Polychlorinated dioxins & Inhaled; animal fat in diet \\
Flame retardant & Polybrominated organics & Domestic environment from use on soft furnishings \\
Plastics, epoxy resins & Bisphenol A & Storage of food and beverages (diet); domestic environment \\
Plastics & Phthalate esters & Domestic consumer products \\
Detergent & Alkyl phenols & Domestic environment \\
Preservative & Parabens & Personal care products, food, pharmaceuticals \\
Antiperspirant & Aluminium chlorohydrate & Underarm antiperspirants \\
Antimicrobial & Triclosan & Personal care products, domestic consumer products \\
Absorb ultraviolet light & Benzophenones & Suncare products, other cosmetics, clothing \\
Fragrance & Butylphenylmethylpropional, & Personal care products, domestic consumer products \\
& benzyl salicylate, musks & \\
Conditioning/spreading agent & Cyclic volatile methylsiloxanes & Personal care products \\
Cigarettes & Cadmium & Cigarette smoking \\
\hline
\end{tabular}

DDT: dichlorodiphenyltrichloroethane

However, endogenous estrogens are also now known to be able to influence cell motility, cell migration and invasive behavior of human breast cancer cells through altering expression of proteins and transcription factors key to the process of epithelial to mesenchymal transition (EMT). EMT is a process in which the epithelial cells lose their polarity and strong cell-cell adhesion properties in order to assume a more mesenchymal phenotype lacking the polarization and the strong cell-cell interactions. The cell adhesion junctions of epithelial cells are reliant on high levels of E-cadherin which is a transmembrane protein linked to the cytoskeleton by $\alpha$ - and $\beta$-catenin, and EMT is typically associated with reduction in levels of these adhesion proteins. It is also associated with altered levels of transcription factors (such as slug and snail) which control expression of the adhesion proteins ${ }^{[7]}$. This allows the cells to break away from neighbouring cells and to become generally more motile. Human breast cancer cell lines which possess $\mathrm{ER} \alpha\left(\mathrm{ER} \alpha^{+}\right)$tend to be less invasive, less metastatic and possess higher levels of E-cadherin than those which lack ER $\alpha(E R \alpha-)^{[11]}$. Knockdown of ER $\alpha$ in the ER $\alpha+$ cell lines has been shown to result in decreased E-cadherin and increased slug expression ${ }^{[12]}$. Conversely, transfected overexpression of ER $\alpha$ in the ER $\alpha$ - cell lines has been shown to enable estrogen-mediated increase in E-cadherin and decrease in slug ${ }^{[12]}$. In the ER $\alpha+$ MCF-7 human breast cancer cell line, estradiol can increase EMT whilst the antiestrogen tamoxifen can reduce $\mathrm{EMT}^{[13]}$ suggesting that the mechanism is ER-dependent. However, there appear to be multiple molecular mechanisms involving not only genomic alterations to levels of E-cadherin and associated transcription factors such as slug ${ }^{[12]}$ but also non-genomic alterations via c-src and phosphorylation of focal adhesion kinase ${ }^{[14,15]}$.

In order to facilitate invasion through local tissue, the cells need also to secrete greater levels of extracellular proteases which aid in the digestion of the surrounding extracellular matrix (ECM). Some of the extracellular proteases identified specifically in human breast cancer cells are matrix metalloproteinases (MMPs) ${ }^{[16,17]}$ and cathepsin $\mathrm{D}^{[18]}$. It is notable that one of the first estrogen-regulated genes to be identified was cathepsin $\mathrm{D}^{[19]}$ and studies now also show effects of estrogen on expression of MMPs ${ }^{[16]}$. These studies attest to the role of estrogen in altering proteases which can degrade the ECM.

Estrogens are also known to play a role in the processes of angiogenesis ${ }^{[10,20]}$. Vascular endothelial growth factor $(V E G F)$ is a key angiogenesis promoting factor and the VEGF gene has been shown to possess functional estrogen response elements indicating it is an estrogen-responsive gene ${ }^{[21]}$. Estrogen treatment 
has also been reported to increase intra-tumoural angiogenesis ${ }^{[22]}$ and VEGF level ${ }^{[23]}$ in mouse models of breast cancer.

\section{ESTROGEN DISRUPTING CHEMICALS AND METASTASIS}

On the basis that endogenous estrogens can influence processes necessary for metastasis, it would seem plausible that estrogen disrupting chemicals will also contribute if they can enter breast tissue and target metastatic tissues at sufficient concentrations. Whilst endogenous estrogens are subject to physiological regulation in terms of both concentration and timing, it is noteworthy that the estrogen disrupting chemicals are not regulated in this manner. The presence of estrogen disrupting chemicals in the body will follow rather intake from environmental exposures balanced by rates of elimination and ability of individual chemicals to bioaccumulate. Many estrogen disrupting chemicals tend to be lipophilic accumulating in body fat over the years such that body burdens increase with age ${ }^{[1]}$. In this context it may be significant that $80 \%$ of breast cancers occur in women over the age of $50^{[24]}$ at a time when endogenous estrogens are reduced following menopause but exogenous estrogen disrupting chemical body burdens would be continuing to increase.

\section{Estrogen disrupting chemicals and metastatic colonisation}

Metastasis of breast cancer cells begins with local spread within the breast and to the underarm lymph nodes. The pattern of more distant dissemination is less predictable with preferred sites of colonization being brain, bone, lungs and liver ${ }^{[7]}$. Stephen Paget's original "seed and soil" hypothesis proposed that preferred sites of metastasis would reflect a favourable organ microenvironment in which the metastatic breast cancer cells could grow ${ }^{[25]}$. His hypothesis was based on the tenet that "when a plant goes to seed, its seeds are carried in all directions, but they can only live and grow if they fall on congenial soil". For breast cancer cells, one important favourable element for cell growth would be an "estrogenic" environment and it is in this context that estrogen disrupting chemicals may influence sites of metastatic spread. Estrogen disrupting chemicals have been widely measured in human populations across the globe in body fluids such as blood and urine and in various body tissues ${ }^{[1]}$. With such widespread contamination of the human body, it is becoming accepted that there are ramifications for human health including effects on male and female reproduction and on cancers in reproductive tissues ${ }^{[1]}$. The presence of estrogen disrupting chemicals across many body tissues could act to change a previously non-favourable location into a favourable environment for colonization and growth of human breast cancer cells into metastatic tumours.

\section{Evidence for effects of estrogen disrupting chemicals on the metastatic process}

There is now mounting evidence for effects of the parabens, ultraviolet (UV) filters, aluminium salts, triclosan, phthalates, bisphenol A (BPA), dioxins and phytoestrogens in the processes of EMT, motility, migration and invasion, and relevant studies of breast cells are discussed below. Most studies to date have been based in vitro but there are some animal models which demonstrate measurable effects also in vivo. Many of the mechanisms may involve mimicking the action of endogenous estrogens through the ability of these estrogen disrupting chemicals to bind to estrogen receptors, but unlike for proliferation, the effects on migration and invasion do not seem to be limited to ER-mediated mechanisms. Furthermore, whilst effects on proliferation can be measured within hours/days of adding an estrogen disrupting chemical to estrogen-responsive breast cells, effects on migration tend to occur after a longer time frame of weeks. The reasons why the time taken is longer remain unknown but would be important to determine in future research.

\section{Parabens}

The alkyl esters of $p$-hydroxybenzoic acid (parabens) are added as preservatives to personal care products, pharmaceuticals and foods ${ }^{[1]}$. Of the five commonly used esters (methylparaben, ethylparaben, 
$n$-propylparaben, $n$-butylparaben and isobutylparaben) $99 \%$ of the human breast tissues were found to contain at least one of the esters, and $60 \%$ contained all five esters ${ }^{[26]}$. Although the parabens bind more weakly to estrogen receptors than do the endogenous estrogens, their efficacy is not weak provided sufficient concentration is present ${ }^{[27]}$. It is therefore noteworthy that the concentrations of parabens measurable to human breast tissues are considerably higher (in the micromolar range) ${ }^{[26]}$ than the levels of endogenous $17 \beta$-estradiol (in the nanomolar range) ${ }^{[2,28]}$. Previous work has demonstrated that parabens can increase proliferation of estrogen-responsive human breast cancer cells in cell culture at concentrations measurable in some human breast tissue samples ${ }^{[2]]}$ through estrogen receptor-mediated mechanisms ${ }^{[27]}$. However, parabens have now been found to also increase migratory and invasive activity of human breast cancer cells in culture ${ }^{[30]}$. Migratory activity was measured using scratch assays, time-lapse microscopy and $\mathrm{xCELLigence} \mathrm{technology}{ }^{[30]}$. Invasive activity was measured using matrix degradation assays and

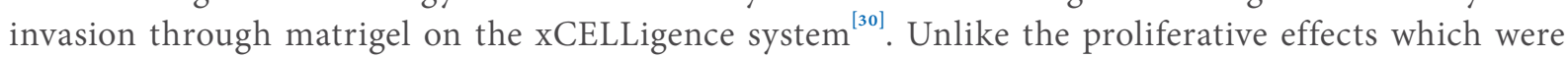
measurable within days of addition of the paraben ${ }^{[27,29]}$, the increased migratory and invasive properties only developed in the cells after long-term exposure (20 weeks) ${ }^{[30]}$. Western immunoblotting showed an associated downregulation of E-cadherin and $\beta$-catenin in the long-term paraben-exposed cells, which could be consistent with a mechanism involving $\mathrm{EMT}^{[30]}$.

One technology which has been particularly useful in determining adhesion, migration and invasion of breast cells following exposure to estrogen disrupting chemicals has been the ACEA BioSciences xCELLigence technology, and the increased cell migration following long-term exposure of MCF-7 human breast cancer cells to paraben which was measured using this technology is shown in Figure 1A. This technology works on the basis of a modified Boyden chamber in which two chambers are separated by a membrane. Migration of cells through the membrane on the base of the upper chamber can be monitored in real time at any pre-determined time interval as the cells move onto the undersurface of this membrane located at the top of the lower chamber. The CIM-plate-16 contains 16 wells which can be monitored independently but simultaneously to measure cell migration/invasion in real time through $8 \mu \mathrm{m}$ pores in the membrane onto gold electrodes on the underside of the membrane using the ACEA BioSciences xCELLigence analyser system. Cell movement onto the gold electrodes is measured as electrical impedance (cell index). Collated traces of cell index are shown in Figure 1A for cell migration through uncoated membranes following 20 weeks of prior treatment with or without $5 \times 10^{-4} \mathrm{M}$ methylparaben or $10^{-5} \mathrm{M}$ n-butylparaben (conditions as published in reference 30).

\section{UV filters}

Chemicals which can absorb UV light (UVA and/or UVB) are added to consumer products either to protect the skin of the user from UV damage (sunscreen products) or to protect the product itself from UV damage during storage ${ }^{[31]}$. They are also used in textiles marketed as UV protective clothing ${ }^{[32]}$. Widespread use of benzophenone-3 (BP-3), octylmethoxycinnamate (OMC) and 4-methylbenzilidenecamphor (4-MBC) has led to their detection in environmental water and soil samples ${ }^{[33]}$ and they have been recently also measured as present in human breast tissues ${ }^{[34]}$. One or more of these UV filters were quantifiable in $84 \%$ of the breast tissue samples and in at least one breast region of $95 \%$ of the women ${ }^{[34]}$. BP-3, OMC and 4-MBC all possess estrogenic activity in reporter gene assays in estrogen-responsive MCF-7 human breast cancer cells $^{[31,35]}$. Long-term exposure (23 weeks) to any one of these three compounds has now also been found to increase migratory activity in MCF-7 cells using scratch assays, time-lapse microscopy and xCELLigence

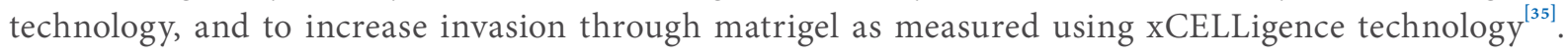
The increased cell migration following long-term treatment (23 weeks) of the MCF-7 cells with or without $10^{-5} \mathrm{M}$ of BP-3 or OMC is shown in Figure $1 \mathrm{~B}$ using xCELLigence technology (conditions as published in reference 35). However, increased motility of estrogen-unresponsive MDA-MB-231 human breast cancer cells was also observed after long-term exposure to each of the three compounds, implying the increased migratory activity was not confined to estrogen responsive cells ${ }^{[35]}$. Furthermore, molecular mechanisms 

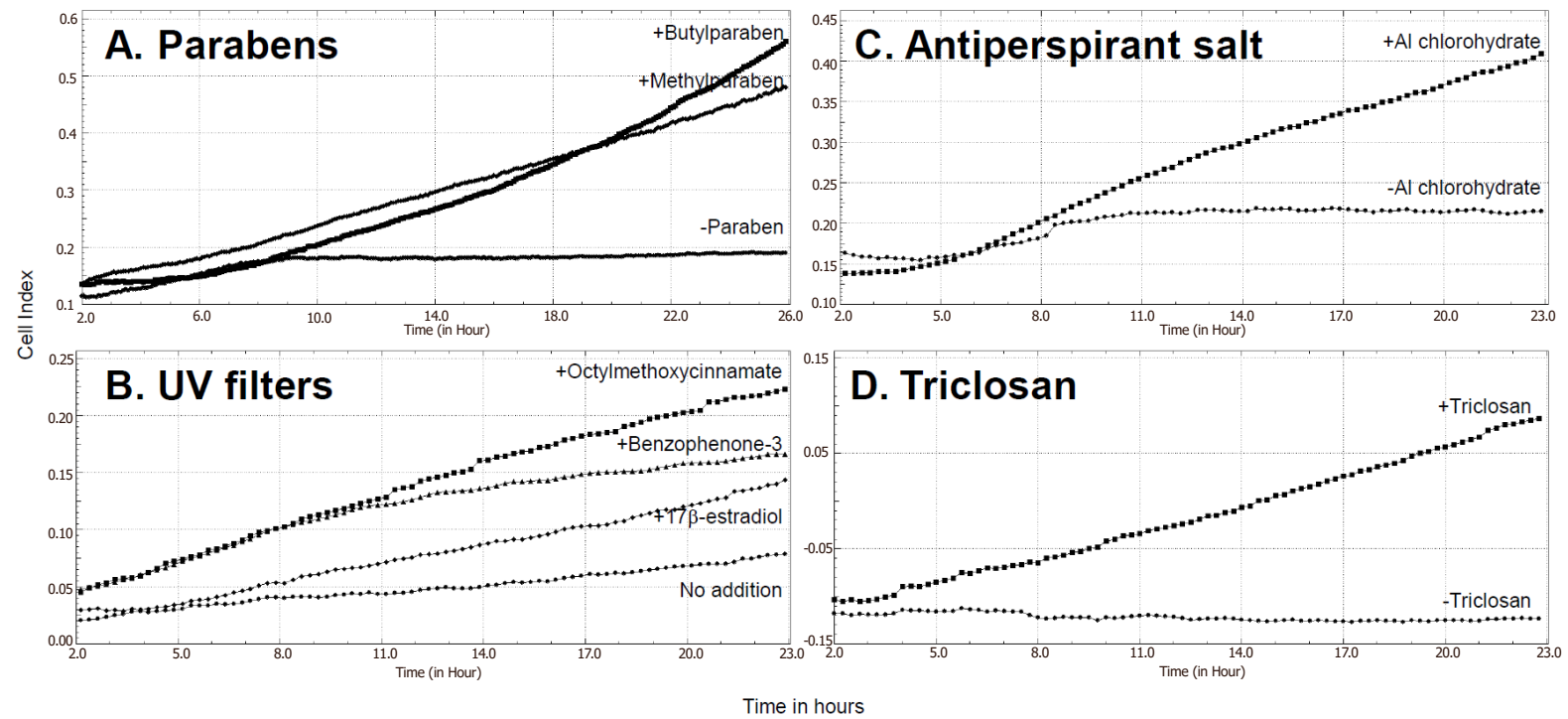

Figure 1. Increases in migration of MCF-7 human breast cancer cells following prior long-term exposure to several estrogen disrupting chemicals contained in personal care products. Cell migration was measured in real-time as electrical impedance (cell index) using xCELLigence technology with uncoated CIM-16 plates. Prior to the assay, cells had been grown. A: for 20 weeks with no addition, $5 \times 10^{-4} \mathrm{M}$ methylparaben or $10^{-5} \mathrm{M}$-butylparaben; $\mathrm{B}$ : for 23 weeks with no addition, $10^{-8} \mathrm{M} 17 \beta$-estradiol, $10^{-5} \mathrm{M}$ octylmethoxycinnamate or $10^{-5} \mathrm{M}$ benzophenone-3; C: for 32 weeks with or without $10^{-4} \mathrm{M}$ aluminium chlorohydrate; D: for 9 weeks with or without $10^{-7} \mathrm{M}$ triclosan. Conditions were as published for the parabens ${ }^{[30]}$, UV filters ${ }^{[35]}$, and aluminium chlorohydrate ${ }^{[42]}$. Data for triclosan are unpublished personal results. UV: ultraviolet

differed between compounds and cell lines, with a noted loss of $\beta$-catenin only after long-term exposure to OMC in the MCF-7 cells and an increase in MMP-2 after long-term exposure to OMC and 4-MBC in the MDA-MB-231 cells ${ }^{[35]}$.

\section{Aluminium-based antiperspirant salts}

Aluminium-based salts are used as antiperspirant in underarm cosmetics and dermal absorption of aluminium from this use has been implicated in the development of breast cancer ${ }^{[36]}$. Aluminium has been measured in human breast tissue ${ }^{[37]}$ and breast cyst fluid ${ }^{[38]}$ at higher levels than in blood, and in nipple aspirate fluid at higher levels in samples taken from women with than without breast cancer ${ }^{[39]}$. Aluminium, as well as several other metal ions, is a metalloestrogen ${ }^{[40]}$ and in the form of the antiperspirant salts aluminium chloride or aluminium chlorohydrate it can displace radiolabeled $17 \beta$-estradiol from estrogen receptors and regulate estrogen-responsive gene expression ${ }^{[4]}$. However, aluminium has also been shown to increase migratory and invasive activity of human breast cancer cells, although since effects were found not only in estrogen-responsive MCF- $7^{[42]}$ but also estrogen-unresponsive MDA-MB-231 ${ }^{[43]}$ cells, estrogen-independent mechanisms of action must also exist. The increased cell migration following longterm (32 weeks) treatment of MCF-7 cells with or without $10^{-4} \mathrm{M}$ aluminium chlorohydrate are illustrated in Figure $1 \mathrm{C}$ using xCELLigence technology (conditions as published in reference 42). More recent animal model research has shown that non-transformed murine mammary gland (NMuMG) epithelial cells exposed to aluminium chloride in vitro were transformed as judged by soft agar assay, and then when injected into three mouse strains with increasing immunodeficiency formed tumours and metastasised in vivo ${ }^{[44]}$. Untreated cells formed tumours and metastasized to a limited extent in the highly immunodeficient and natural killer (NK) cell deficient NSG mouse strain but not in the less permissive and NK cell competent NOD SKID strain or nude strains. In contrast, NMuMG cells transformed in vitro by the aluminium chloride formed large tumours and metastasized in all three mouse models ${ }^{[4]}$. 


\section{Triclosan}

Triclosan [5-chloro-2-(2,4-dichlorophenoxy)phenol] is a chlorinated aromatic compound which is added as a broadspectrum antimicrobial agent to consumer goods. It was first used as a hospital scrub but is now added widely to personal care products and homeware products ${ }^{[45]}$. It possesses estrogenic activity ${ }^{[46]}$ and has been detected in human milk ${ }^{[45]}$ implying its presence in the human breast. It can increase proliferation of estrogen-responsive human breast cancer cells ${ }^{[45]}$. More recently, exposure of MCF-7 human breast cancer cells to triclosan has been shown to increase migration and development of EMT associated with downregulation of E-cadherin and upregulation of $\mathrm{N}$-cadherin, snail and slug ${ }^{[47]}$. The increased cell migration observed in our laboratory following long-term (9 weeks) exposure of MCF-7 cells to $10^{-7} \mathrm{M}$ triclosan is shown in Figure 1D using xCELLigence technology (personal unpublished data).

\section{Phthalates}

Esters of phthalic acid (phthalates) are used as plasticisers in the manufacture of plastics. However, in addition to plastic goods, they are also found in many personal care products, adhesives, paints, air fresheners, food products, pharmaceuticals and textiles ${ }^{[1]}$. Many of the esters are listed by the Organisation for Economic Cooperation and Development (OECD) as high production volume chemicals ${ }^{[48]}$, with some of the most used being diethylphthalate (DEP), dibutylphthalate (DBP), benzylbutylphthalate (BBP) and di(2-ethylhexyl)phthalate (DEHP). Metabolites of these esters are widely detected in human urine samples of the US population ${ }^{[49]}$ and can be measured in human milk ${ }^{[50]}$ implying their presence in the human breast. Many of these widely used esters and their metabolites possess estrogenic activity and can increase growth of estrogen-responsive human breast cancer cells ${ }^{[51,52]}$. Using a stem cell-derived human breast epithelial cell line R2d, DBP and BBP were found to induce EMT through an ER-mediated increase in mesenchymal markers and decrease in epithelial markers ${ }^{[53]}$. Furthermore, BBP has been reported to increase growth of tumours and lung-derived metastases in an in vivo mouse xenograft model using breast cancer stem cells. The mechanism was linked to an arylhydrocarbon receptor-mediated increase in sphingosine-1-phosphate receptor $3\left(\mathrm{~S}_{1} \mathrm{PR} 3\right)$ signaling since downregulation of this pathway reduced both the tumour growth and the lung metastasis but the role of estrogen in this remains unknown ${ }^{[54]}$.

\section{Bisphenol A}

BPA is used in the manufacture of polycarbonate plastics and epoxy resins which are found ubiquitously in building materials and consumer products ${ }^{[55]}$. It is used to line food storage containers and water bottles from which it can leach out when heated ${ }^{[56]}$. It is listed by the OECD as a high production volume chemical $^{[48]}$. A large literature links BPA to adverse health effects in animals and humans ${ }^{[55]}$, and it is measurable in human body tissues including breast milk ${ }^{[57]}$ which implies its presence in the human breast. Through its estrogenic activity, it is known to stimulate the proliferation of estrogen-responsive human breast cancer cells ${ }^{[56]}$. Animal models have revealed that prenatal exposure can enhance breast carcinogenesis in the chemically induced DMBA-mouse model ${ }^{[58]}$ and alone can also cause disruption to the mouse mammary tissue increasing susceptibility to breast cancer ${ }^{[59]}$. However, chronic exposure to BPA in drinking water during adulthood was also shown to increase tumour burden and incidence of metastasis in a transgenic mouse model that spontaneously develops tumors through overexpression of erbB2 ${ }^{[60]}$. More recent in vitro experiments with human breast cancer cells are beginning to suggest that BPA may increase cell migration and invasion. Exposure of SkBr3 human breast cancer cells to BPA (10 $\left.{ }^{-8} \mathrm{M}\right)$ increased cell motility and downregulated the transcription factor FOXA1 ${ }^{[61]}$. FOXA1 repression is thought to be characteristic of EMT because it is an activator of the E-cadherin gene ${ }^{[62]}$. Exposure of the human breast cancer cell lines MDA-MB-231 and BT-549 led to increased invasiveness with an associated increased expression of MMP-2 and MMP-9 ${ }^{[63]}$.

\section{Dioxins}

Polychlorinated dibenzodioxins (PCDDs) (dioxins) are highly toxic, bioaccumulative environmental pollutants generated as byproducts of combustion ${ }^{[64]}$. They are carried by air, washed off the land by 
rainwater into rivers and lakes and then pass up the food chain dissolved in animal fat. They are measured ubiquitously in human tissues ${ }^{[64]}$. There are 75 congeners of which the most toxic is 2,3,7,8-tetrachlorodi benzodioxin (TCDD) ${ }^{[64]}$ and has been shown to exert molecular actions both through ER-mediated and AhR-mediated mechanisms ${ }^{[6]}$. Gene targets of the AhR include activation of slug and some MMPs ${ }^{[66]}$. In the ER+, AhR+ MCF-7 human breast cancer cells, TCDD has been found to downregulate E-cadherin and reduce cell-cell contacts in a JNK-dependent mechanism ${ }^{[67]}$. However, antiestrogenic actions of TCDD have been repeatedly reported over the years ${ }^{[65]}$, and so it is noteworthy that TCDD has been reported to inhibit mammary tumour metastasis in vivo ${ }^{[68,69]}$.

\section{Phytoestrogens}

Phytoestrogens are found in over 300 plant species and can be ingested by humans through consumption of plant material either in diet or as dietary supplements ${ }^{[70]}$. Flavonoids include genistein and daidzein found in soybeans and other legumes, coumestans in clover and young sprouting legumes, prenylflavonoids in hops. The most prevalent non flavonoids are lignans in cereals, fruits and vegetables. Although many purified phytoestrogens display estrogenic activity in vitro, the estrogenic actions on cell proliferation are concentration-dependent with only the lower doses increasing proliferation of estrogen-responsive human breast cancer cells, whilst higher doses inhibit ${ }^{[7]}$, and many phytoestrogen-containing plant products are considered to have anti-tumour activity ${ }^{[70]}$. It is interesting therefore that emerging data seem to suggest that several phytoestrogens can act to reduce breast cancer cell migration and invasion including lignans ${ }^{[72]}$, soy-derived daidzein ${ }^{[73]}$, and formononetin ${ }^{[74]}$. Triclosan-induced EMT can be reversed by kaempferol ${ }^{[47]}$. However, one mouse model of breast cancer has shown that consumption of soy isoflavones increased growth of metastatic tumours in bone and lung ${ }^{[75]}$.

\section{THE ISSUE OF LOW-DOSE MIXTURES}

The studies discussed above provide evidence that some individual estrogen disrupting chemicals can influence components of EMT and processes of migration and invasion in human breast cancer cells. However, since many hundreds of estrogen disrupting chemicals have now been measured in the human breast $^{[1]}$, the environmental reality is that, in today's world, human breast cells in vivo are not exposed to single chemicals but to complex mixtures of pollutant chemicals. This is especially poignant in view of many estrogen disrupting chemicals being lipophilic and the human breast being a fatty organ. It is also highly relevant in the context of the many non-monotonic responses which have been reported for environmental endocrine disrupting chemicals in general, often with stronger responses at the relatively lower doses tested ${ }^{[76]}$. There are therefore outstanding questions as to the effects of exposure to complex mixtures of estrogen disrupting chemicals where each is present at low dose. For proliferation, it has been shown that mixtures of such chemicals can increase cell proliferation where the same concentrations of the estrogen disrupting chemicals individually do not, in what has now been nicknamed "the something from nothing" effect ${ }^{[77]}$. Even mixtures of the different esters of parabens can add together to give increased cell proliferation ${ }^{[2]}$. This is relevant environmentally where human breast tissue samples were found to contain differing levels of the individual paraben esters ${ }^{[26]}$ and implies that the same outcomes can arise from different mixtures of estrogen disrupting chemicals ${ }^{[2]}$. Clearly in ER-mediated mechanisms, such as in increasing cell proliferation, each chemical will act according to its relative estrogen receptor binding affinity but low doses of different chemicals can add together until a maximum proliferative signal is achieved. As yet, there seems to be no published information as to whether the same effect of mixtures can be achieved on development of EMT or on increasing cell migration/invasion. Furthermore, since these studies are technically long and labour-intensive, the range of concentrations are often lacking in order to determine the extent to which non-monotonic responses may be occurring. 


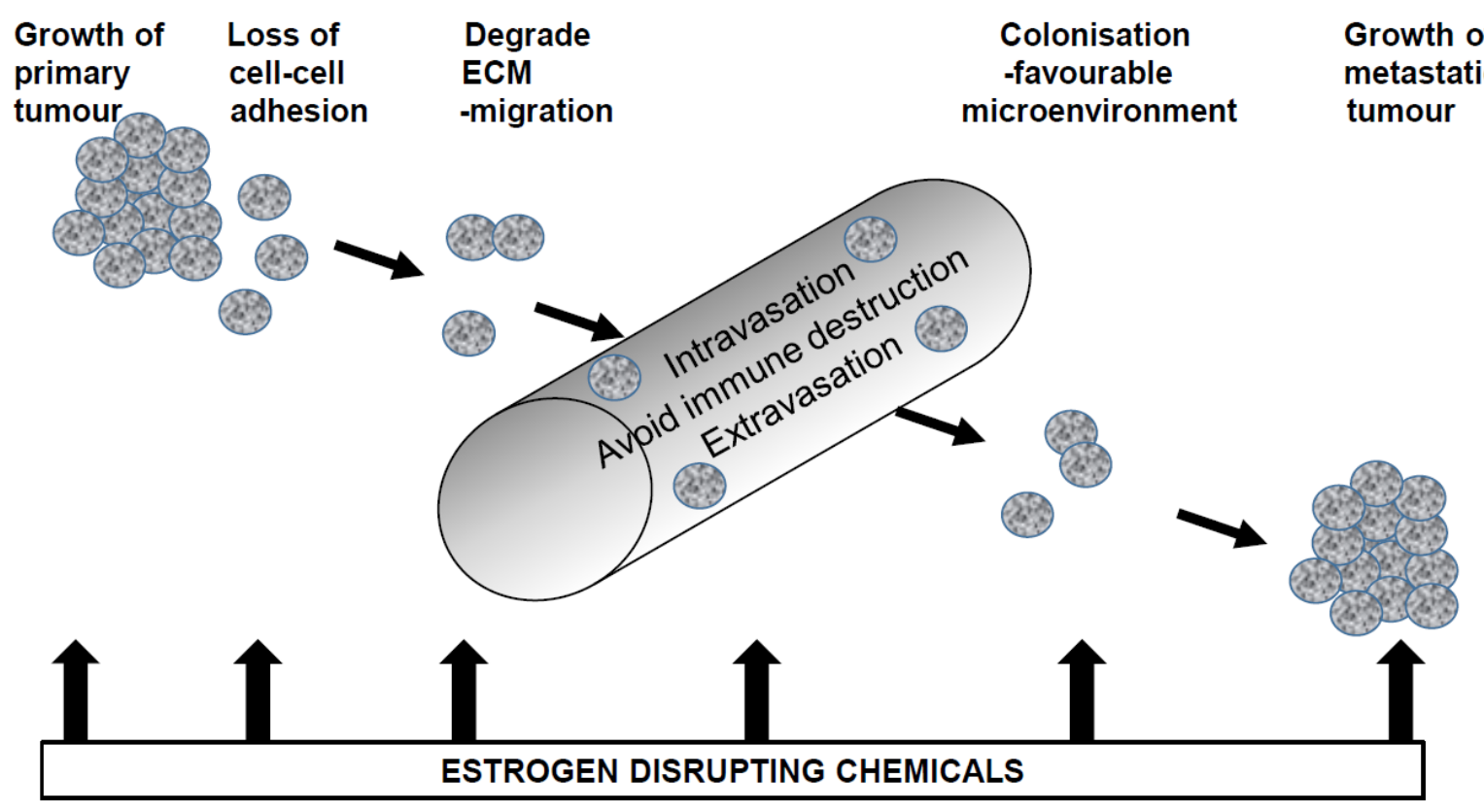

Figure 2. Diagrammatic representation of how estrogen disrupting chemicals may influence metastasis of breast cancer cells. Through their estrogenic activity, they may increase growth of cells at the primary site in the breast or at metastatic sites. They may enable EMT, increase cell migration and cell invasion. Through their widespread presence in the human body, they may provide a favourable microenvironment for colonization and metastatic tumour growth

\section{CONCLUSIONS}

It can be concluded that there is mounting evidence for a role of estrogen disrupting chemicals in contributing to the processes of metastatic tumour spread and this is summarized in Figure 2. Estrogen disrupting chemicals may contribute to loss of cell-cell adhesion, development of EMT and increased secretion of ECM-degrading proteases leading to increased cell motility, migration and invasion. However, estrogen disrupting chemicals are also likely to play a role in creating a favourable microenvironment for colonization and growth of metastatic tumours at distant sites. Unpredictable awakening from dormancy ${ }^{[7]}$ could result from altered environmental exposures or indeed sudden release of estrogen disrupting chemicals from fat stores such as at times of weight loss. It is well established that estrogen disrupting chemicals are passed from mother to child in breast milk as they are mobilized with the fat in the milk ${ }^{[78]}$. Such detoxification of the the mother's breast may provide an alternative explanation for the protective effect of breast feeding on incidence of breast cancer $^{[77]}$. Likewise, release of estrogen disrupting chemicals from storage could change the microenvironment for "dormant niches" ${ }^{\text {s[] }}$ causing renewed proliferation.

Research is now needed to answer outstanding questions concerning the effects of long-term exposure to low doses of chemicals and the effects of complex mixtures of chemicals ${ }^{[80]}$. Since estrogen disrupting chemicals are widely measurable in human tissues and some can bioaccumulate with age, then it follows that breast cells are exposed long term which requires long term cell culture modelling for further understanding. This is especially poignant in the acquisition of increased migratory and invasive properties described above which generally took weeks rather than days to develop. The effects of mixtures of chemicals each at low dose will be more difficult to resolve because personal lifestyle choices will inevitably result in differing chemical contents between individuals. Furthermore, due to the additive and complementary mechanisms of estrogen disrupting chemicals ${ }^{[81]}$, different mixtures may have the same outcomes which makes tracing individual culprit chemicals impossible. However, if specific environmental exposures can be uncovered, then avoidance would be a good strategy for prevention. In 2001, I proposed a hypothesis that regular application of constituents of underarm cosmetics might play a role in the rising 
incidence of breast cancer if sufficient of the constituent chemicals were absorbed either from long-term exposure on the skin (these products are not washed off) or from damaging the skin by shaving prior to cosmetic application ${ }^{[82,83]}$. This was proposed partly due to the disproportionately high incidence of breast cancer in the upper outer quadrant of the breast which is coincidentally also the site of application of these chemicals. Many years on, it is now known that many of the constituent chemicals can be absorbed through even intact skin after a single application ${ }^{[84,85]}$ and that they are measurable in human breast tissue or human milk (see above for references). Published studies have linked the levels of some of these estrogen disrupting chemicals in the body tissues with personal care product usage ${ }^{[86,87]}$. However, it is also clear that these chemicals are getting into many body tissues other than breast and therefore could be expected to create distant estrogenic microenvironments which could influence not only the growth of the primary tumour but also growth of metastatic tumours. If excessive use of personal care products is involved in the development of metastatic breast cancer, then reduction or cessation in use could provide a prevention strategy.

\section{DECLARATIONS}

\section{Authors' contributions}

This review was written solely by the author and reflects the author's views.

\section{Availability of data and materials}

Not applicable.

\section{Financial support and sponsorship}

None.

\section{Conflicts of interest}

The author declares that there are no conflicts of interest.

\section{Ethical approval and consent to participate}

Not applicable.

\section{Consent for publication}

Not applicable.

\section{Copyright}

(c) The Author(s) 2019.

\section{REFERENCES}

1. Darbre PD. Endocrine disruption and human health. New York: Elsevier; 2015.

2. Miller WR. Estrogen and Breast Cancer. London: Chapman and Hall; 1996.

3. Hanahan D, Weinberg RA. Hallmarks of cancer: the next generation. Cell 2011;144:646-74.

4. Darbre PD. Molecular mechanisms of oestrogen action on growth of human breast cancer cells in culture. Horm Mol Biol Clin Invest 2012;9:65-95.

5. Engstrom W, Darbre P, Eriksson S, Gulliver L, Hultman T, et al. The potential for chemical mixtures from the environment to enable the cancer hallmark of sustained proliferative signaling. Carcinogenesis 2015;36: S38-S60.

6. Russo J, Russo IH. The role of estrogen in the initiation of breast cancer. J Steroid Biochem Molec Biol 2006;102:89-96.

7. Lambert AW, Pattabiraman DR, Weinberg RA. Emerging biological principles of metastasis. Cell 2017;168:670-91.

8. Arnal JF, Lenfant F, Metivier R, Flouriot G, Henrion D, et al. Membrane and Nuclear Estrogen Receptor Alpha Actions: From Tissue Specificity to Medical Implications. Physiol Rev 2017;97:1045-87.

9. Barton M, Filardo EJ, Lolait SJ, Thomas P, Magglioni M, et al. Twenty years of the G protein-coupled estrogen receptor GPER: Historical and personal perspectives. J Ster Biochem Molec Biol 2018;176: 4-15. 
10. Nair S, Sachdeva G. Estrogen matters in metastasis. Steroids 2018;38:108-16

11. Price JE, Zhang RD. Studies of human breast cancer metastasis using nude mice. Cancer Metastasis Rev 1990;8:285-97.

12. Ye Y, Xiao Y, Wang W, Yearsley K, Gao JX, et al. ER signaling through slug regulates E-cadherin and EMT. Oncogene 2010;29:1451-62.

13. Planas-Silva MD, Waltz PK. Estrogen promotes reversible epithelial-to-mesenchymal transition and collective motility in MCF-7 breast cancer cells. J Steroid Biochem Molec Biol 2007;104:11-21.

14. Li Y, Wang JP, Santen RJ, Kim TH, Park H, et al. Estrogen stimulation of cell migration involves multiple signaling pathway interactions. Endocrinol 2010;151:5146-56.

15. Sanchez AM, Flamini MI, Baldacci C, Goglia L, Genazzani AR, et al. Estrogen receptor-promotes breast cancer cell motility and invasion via focal adhesion kinase and N-WASP. Mol Endocrinol 2010;24:2114-25.

16. Kohrmann A, Kammerer U, Kapp M, Dietl J, Anaker J. Expression of matrix metalloproteinases (MMPs) in primary human breast cancer and breast cancer cell lines: New findings and review of the literature. BMC Cancer 2009;9: 188.

17. Kessenbrock K, Plaks V, Werb Z. Matrix metalloproteinases: regulators of the tumor microenvironment. Cell 2010;141:52-67.

18. Dian D, Heublein S, Wiest I, Barthell L, Friese K, et al. Significance of the tumor protease cathepsin D for the biology of breast cancer. Histol Histopathol 2014;29:433-8.

19. Morisset M, Capony F, Rochefort H. The 52-kDa estrogen-induced protein secreted by MCF7 cells is a lysosomal acidic protease. Biochem Biophys Res Commun 1986;138:102-9.

20. Takei H, Lee ES, Jordan VC. In vitro regulation of vascular endothelial growth factor by estrogens and antiestrogens in estrogenreceptor positive breast cancer. Breast Cancer 2002;9: 39.

21. Hyder SM, Nawaz Z, Chiappetta C, Stancel GM. Identification of functional estrogen response elements in the gene encoding for the potent angiogenic factor vascular endothelial growth factor. Cancer Res 2000;60:3183-90.

22. Dabrosin C, Palmer K, Muller WJ, Gaudlie J. Esradiol promotes growth and angiogenesis in polyoma middle T transgenic mouse mammary tumor explants. Breast Cancer Res Treat 2003;78:1-6.

23. Dabrosin C, Margetts PJ, Gauldie J. Estradiol increases extracellular levels of vascular endothelial growth factor in vivo in murine mammary cancer. Int J Cancer 2003;107:535-40.

24. Office of National Statistics, England. Series MB1, Published Crown Copyright, London. from 1979 to 2014 (MBseries 1 numbered to 43$)$.

25. Paget S. The distribution of secondary growths in cancer of the breast. Lancet 1889;133:571-3.

26. Barr L, Metaxas G, Harbach CAJ, Savoy LA, Darbre PD. Measurement of paraben concentrations in human breast tissue at serial locations across the breast from axilla to sternum. J Appl Toxicol 2012;32:219-32.

27. Byford JR, Shaw LE, Drew MGB, Pope GS, Sauer MJ, et al. Oestrogenic activity of parabens in MCF7 human breast cancer cells. J Steroid Biochem Molec Biol 2002;80:49-60.

28. Wright JV, Schliesman B, Robinson L. Comparative measurements of serum estriol, estradiol, and estrone in non-pregnant, premenopausal women: a preliminary investigation. Alt Med Rev 1999;4:266-70.

29. Charles AK, Darbre PD. Combinations of parabens at concentrations measured in human breast tissue can increase proliferation of MCF-7 human breast cancer cells. J Appl Toxicol 2013;33:390-8.

30. Khanna S, Dash PR, Darbre PD. Exposure to parabens at the concentration of maximal proliferative response increases migratory and invasive activity of human breast cancer cells in vitro. J Appl Toxicol 2014;34:1051-9.

31. Schlumpf M, Cotton B, Conscience M, Haller V, Steinmann B, et al. In vitro and in vivo estrogenicity of UV screens. Environ Health Perspect 2001;109: 239-44.

32. Hoffmann K, Laperre J, Avermaete A, Altmeyer P, Gambichler T. Defined UV protection by apparel textiles. Arch Dermatol 2001;137: 1089-94.

33. Montes-Grajales D, Fennix-Agudelo M, Miranda-Castro W. Occurrence of personal care products as emerging chemicals of concern in water resources: A review. Sci Total Environ 2017;595:601-14.

34. Barr L, Alamer M, Darbre PD. Measurement of concentrations of four chemical ultraviolet filters in human breast tissue at serial locations across the breast. J Appl Toxicol 2018;38:1112-20.

35. Alamer M, Darbre PD. Effects of exposure to six chemical ultraviolet filters commonly used in personal care products on motility of MCF-7 and MDA-MB-231 human breast cancer cells in vitro. J Appl Toxicol 2018;38:148-59.

36. Darbre PD. Aluminium and the human breast. Morphologie 2016;100:65-74

37. Exley C, Charles LM, Barr L, Martin C, Polwart A, et al. Aluminium in human breast tissue. J Inorg Biochem 2007;101:1344-6.

38. Mannello F, Tonti GA, Darbre PD. Concentration of aluminium in breast cyst fluids collected from women affected by gross cystic breast disease. J Appl Toxicol 2009;29:1-6.

39. Mannello F, Tonti GA, Medda V, Simone P, Darbre PD. Analysis of aluminium content and iron homeostasis in nipple aspirate fluids from healthy women and breast cancer-affected patients. J Appl Toxicol 2011;31:262-9.

40. Darbre PD. Metalloestrogens: an emerging class of inorganic xenoestrogens with potential to add to the oestrogenic burden of the human breast. J Appl Toxicol 2006;26:191-7.

41. Darbre PD. Aluminium, antiperspirants and breast cancer. J Inorg Biochem 2005;99:1912-9.

42. Darbre PD, Bakir A, Iskakova E. Effect of aluminium on migratory and invasive properties of MCF-7 human breast cancer cells in culture. J Inorg Biochem 2013;128:245-9.

43. Bakir A, Darbre PD. Effect of aluminium on migration of oestrogen unresponsive MDA-MB-231 human breast cancer cells in culture. 
J Inorg Biochem 2015;152:180-5.

44. Mandriota SJ, Tenan M, Ferrari P, Sappino AP. Aluminium chloride promotes tumorigenesis and metastasis in normal murine mammary gland epithelial cells. Int J Cancer 2016;139:2781-90.

45. Dann AB, Hontela A. Triclosan: environmental exposure, toxicity and mechanisms of action. J Appl Toxicol 2011;31:285-311.

46. Gee RH, Charles A, Taylor N, Darbre PD. Oestrogenic and androgenic activity of triclosan in breast cancer cells. J Appl Toxicol 2008;28:78-91.

47. Lee GA,Choi KC, Hwang KA. Kaempferol, a phytoestrogen, suppressed triclosan-induced epithelial-mesenchymal transition and metastatic-related behaviors of MCF-7 breast cancer cells. Environ Toxicol Pharmacol 2017;49:48-57.

48. Organisation for Economic Cooperation and Development (OECD). The 2004 OECD List of High Production Volume Chemicals. Environment Directorate, Paris, 2004.

49. Silva MJ, Barr DB, Reidy JA, Malek NA, Hodge CC, et al. Urinary levels of seven phthalate metabolites in the U.S. population from the National Health and Nutrition Examination Survey (NHANES) 1999-2000. Environ Health Perspect 2004;112:331-8.

50. Schlumpf M, Kypke K, Wittassek M, Angerer J, Mascher H, et al. Exposure patterns of UV filters, fragrances, parabens, phthalates, organochlorpesticides, PBDEs and PCBs in human milk: Correlation of UV filters with use of cosmetics. Chemosphere 2010;81:117183.

51. Jobling S, Reynolds T, White R, Parker MG, Sumpter JP. A variety of environmentally persistent chemicals, including some phthalate plasticizers, are weakly estrogenic. Environ Health Perspect 1995;103:582-7.

52. Harris CA, Henttu P, Parker MG, Sumpter JP. The estrogenic activity of phthalate esters in vitro. Environ Health Perspect 1997; 105:802-11.

53. Hsieh TH, Tsai CF, Hsu CY, Kuo PL, Lee JN, et al. Phthalates stimulate the epithelial to mesenchymal transition through an HDAC6dependent mechanism in human breast epithelial stem cells. Toxicol Sci 2012;128:365-76.

54. Wang YC, Tsai CF, Chuang HL, Chang YC, Chen HS, et al. Benzyl butyl phthalate promotes breast cancer stem cell expansion via SPHK1/S1P/S1PR3 signaling. Oncotarget 2016;7:29563-76.

55. Rochester JR. Bisphenol A and human health: a review of the literature. Reprod Toxicol 2013;42:132-55.

56. Krishnan AV, Stathis P, Permuth SF, Tokes L, Feldman D. Bisphenol-A: an estrogenic substance is released from polycarbonate flasks during autoclaving. Endocrinol 1993;132:2279-86.

57. Hines EP, Mendola P, von Ehrenstein OS, Ye X, Calafat AM, et al. Concentrations of environmental phenols and parabens in milk, urine and serum of lactating North Carolina women. Reprod Toxicol 2015;54:120-8.

58. Jenkins S, Raghuraman N, Eltoum I, Carpenter M, Russo J, et al. Oral exposure to bisphenol A increases dimethylbenzanthraceneinduced mammary cancer in rats. Environ Health Perspect 2009;117:910-915.

59. Lozada KW, Keri RA. Bisphenol A increases mammary cancer risk in two distinct mouse models of breast cancer. Biol Reprod 2011;85:490-7.

60. Jenkins S, Wang J, Eltoum I, Desmond R, Lamartiniere CA. Chronic oral exposure to bisphenol A results in a nonmonotonic dose response in mammary carcinogenesis and metastasis in MMTV-erbB2 mice. Environ Health Perspect 2011;119:1604-9.

61. Zhang XL, Wang HS, Liu N, Ge LC. Bisphenol A stimulates the epithelial mesenchymal transition of estrogen negative breast cancer cells via FOXA1 signals. Arch Biochem Biophys 2015;585:10-6.

62. Song Y, Washington MK, Crawford HC. Loss of FOXA1/2 is essential for the epithelial-to-mesenchymal transition in pancreatic cancer. Cancer Res 2010;70:2115-25.

63. Zhang XL, Liu N, Weng SF, Wang HS. Bisphenol A increases the migration and invasion of triple-negative breast cancer cells via oestrogen-related receptor gamma. Basic Clin Pharmacol Toxicol 2016;119:389-95.

64. World Health Organisation. Polychlorinated dibenzo-p-dioxins and dibenzofurans. Environmental Health Criteria 1989; Number 88.

65. Safe S, Wormke M. Inhibitory aryl hydrocarbon receptor-estrogen receptor cross-talk and mechanisms of action. Chem Res Toxicol 2003;16:807-16.

66. Ikuta T, Kawajiri K. Zinc finger transcription factor Slug is a novel target gene of aryl hydrocarbon receptor. Exp Cell Res 2006;312:3585-94.

67. Diry M, Tomkiewicz C, Koehle C, Coumoul X, Bock KW, et al. Activation of the dioxin/aryl hydrocarbon receptor (AhR) modulates cell plasticity through a JNK-dependent mechanism. Oncogene 2006;25:5570-4.

68. Wang T, Wyrick KL, Meadows GG, Wills TB, Vorderstrasse BA. Activation of the aryl hydrocarbon receptor by TCDD inhibits mammary tumor metastasis in a syngeneic mouse model of breast cancer. Toxicol Sci 2011;124:291-8.

69. Zhang S, Kim K, Jin UH, Pfent C, Cao H, et al. Aryl hydrocarbon receptor agonists induce microRNA-335 expression and inhibit lung metastasis of estrogen receptor negative breast cancer cells. Cancer Ther 2012;11:108-18.

70. Woods HF (chairman). Phytoestrogens and health. Crown copyright, 2003.

71. Matsumura A, Ghosh A, Pope GS, Darbre PD. Comparative study of oestrogenic properties of eight phytoestrogens in MCF7 human breast cancer cells. J Steroid Biochem Mol Biol 2005;94:431-43.

72. Chen J, Thompson LU. Lignans and tamoxifen, alone or in combination, reduce human breast cancer cell adhesion, invasion and migration in vitro. Breast Cancer Res Treat 2003;80:163-70.

73. Bao C, Namgung H, Lee J, Park HC, Ko J, et al. Daidzein suppresses tumor necrosis factor- $\alpha$ induced migration and invasion by inhibiting hedgehog/Gli1 signaling in human breast cancer cells. J Agric Food Chem 2014;62:3759-67.

74. Zhou R, Xu L, Ye M, Liao M, Du H, et al. Formononetin inhibits migration and invasion of MDA-MB-231 and 4T1 breast cancer cells by suppressing MMP-2 and MMP-9 through PI3K/AKT signaling pathways. Horm Metab Res 2014;46:753-60. 
75. Yang X, Belosay A, Hartman JA, Song H, Zhang Y, et al. Dietary soy isoflavones increase metastasis to lungs in an experimental model of breast cancer with bone micro-tumors. Clin Exp Metastasis 2015;32:323-33.

76. Vandenberg LN, Colborn T, Hayes TB, Heindel JJ, Jacobs DR, et al. Hormones and endocrine-disrupting chemicals: low-dose effects and nonmonotonic dose responses. Endocrine Rev 2012;33:378-455.

77. Rajapakse N, Silva E, Kortenkamp A. Combining xenoestrogens at levels below individual no-observed-effect concentrations dramatically enhances steroid hormone action. Environ. Health Perspect 2002;110:917-21.

78. Van Den Berg M, Kypke K, Kotz A, Tritscher A, Lee SY, et al. WHO/UNEP global surveys of PCDDs, PCDFs, PCBs and DDTs in human milk and benefit-risk evaluation of breastfeeding. Arch Toxicol 2017;91:83-96.

79. Key TJ, Verkasalo PK, Banks E. Epidemiology of breast cancer. The Lancet Oncology 2011;2:133-40.

80. Goodson WH, Lowe L, Carpenter DO, Gilbertson M, Ali AM, et al. Assessing the carcinogenic potential of low-dose exposures to chemical mixtures in the environment: the challenge ahead. Carcinogenesis 2015;36:254-96.

81. Darbre PD, Fernandez MF. Environmental oestrogens and breast cancer: long-term low-dose effects of mixtures of various chemical combinations. J Epidemiol Commun Health 2013;67:203-5.

82. Darbre PD. Hypothesis: Underarm cosmetics are a cause of breast cancer. Eur J Cancer Prevent 2001;10:389-93.

83. Darbre PD. Underarm cosmetics and breast cancer. J Appl Toxicol 2003;23:89-95.

84. Janjua NR, Mogensen B, Andersson AM, Petersen JH, Henriksen M, et al. Systemic absorption of the sunscreens benzophenone-3, octyl-methoxycinnamate, and 3-(4-methyl-benzilidene) camphor after whole-body topical application and reproductive hormone levels in humans. J Invest Dermatol 2004;123:57-61.

85. Janjua NR, Mortensen GK, Andersson AM, Kongshoj B, Skakkebaek NE, et al. Systemic uptake of diethyl phthalate, dibutyl phthalate, and butyl paraben following whole-body topical application and reproductive and thyroid hormone levels in humans. Environ. Sci Technol 2007;41:5564-70.

86. Calafat AM, Wong LY, Ye X, Reidy JA, Needham LL. Concentrations of the Sunscreen Agent Benzophenone-3in Residents of the United States: National Health and Nutrition Examination Survey 2003-2004. Environ Health Perspect 2008;116:893-7.

87. Sandanger TM, Huber S, Moe MK, Braathen T, Leknes H, et al. Plasma concentrations of parabens in postmenopausal women and self-reported use of personal care products: the NOWAC postgenome study. J Expo Sci Environ Epidemiol 2011;21:595-600. 